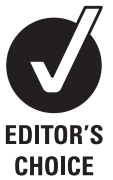

CHOICE

\title{
The implications of the NICE guidelines on neurosurgical management for all severe head injuries: systematic review
}

\author{
Helen Barratt, ${ }^{1}$ Mark Wilson, ${ }^{2}$ Fionna Moore, ${ }^{3}$ Rosalind Raine ${ }^{4}$
}

${ }^{1}$ Department of Epidemiology and Public Health, University College London, London, UK ${ }^{2}$ The National Hospital for Neurology and Neurosurgery, Queen Square, London, UK ${ }^{3}$ London Ambulance Service NHS Trust/Consultant in Emergency Medicine, Imperial College Healthcare NHS Trust, London, UK

${ }^{4}$ Professor of Health Care Evaluation, Department of Epidemiology and Public Health, University College London, London, UK

\section{Correspondence to}

Dr Helen Barratt, Academic Clinical Fellow, Health Care Evaluation Group, Dept Epidemiology and Public Health, University College London, 1-19 Torrington Place, London WC1E 6BT, UK; h.barratt@ public-health.ucl.ac.uk

Accepted 24 August 2009

\section{ABSTRACT}

Head injury is an important cause of death among young adults in the UK, and a significant burden on NHS resources. However, management is inconsistent, governed largely by local resources.

The latest version of the NICE head injury guidelines suggests that more patients with traumatic brain injury should be transferred to receive specialist care. However, this raises issues about the capacity of regional neurosurgical units, particularly to accommodate patients who do not require surgical intervention.

Objectives To critically evaluate the basis of the NICE recommendations about transfer for neurosurgical care, and examine the configuration of specialist services to assess the implications of increasing the existing number of transfers.

Methods A systematic literature review was conducted of articles discussing the provision of emergency neurosurgical care for adult head injuries in the UK.

Results Fifty-eight papers met the criteria for inclusion in the literature review, including seven papers cited in the NICE guidance. Fifty-one papers related to neurosurgical care, including papers on bed occupancy, transfer times and transfer policies.

Conclusions The evidence NICE cited is of variable quality. Much of the research was conducted outside the UK, which raises questions about its relevance to the NHS. Care of traumatic brain injuries in the UK is already hampered by the inadequate capacity of regional neurosurgical units to meet demand, and transferring more patients would be likely to exacerbate this. Increasing the number of transfers could also worsen inequalities of access for other groups, such as elective patients, particularly in areas where facilities are most stretched.

\section{INTRODUCTION}

Head injury is among the most important causes of death in young adults in the UK and patients who survive often experience long-term disability. ${ }^{1}$ Eleven million patients present to hospital with a head injury each year, ${ }^{2}$ and, although only $5 \%$ are severe (Glasgow Coma Score $\leq 8 / 15$ ), around 4000 will require neurosurgery. ${ }^{3}$ The acute care of patients with severe injury costs the NHS over $£ 1$ billion annually. ${ }^{4}$

Despite technical progress, such as wider availability of computed tomography (CT) scanning and advances in specialist neurocritical care, ${ }^{5}$ there has been little improvement in outcomes following head injury since $1994 .^{6}$ Management is inconsistent, governed largely by local practice and resources, ${ }^{7}$ with a lack of neurosurgical beds and regional variations in availability. ${ }^{9} 10$

Most patients with traumatic brain injury (TBI) are taken by ambulance to the nearest district general hospital (DGH) with trauma facilities for initial stabilisation. Those who require neurosurgery must then be transferred to the regional neurosciences unit (RNU) for definitive management. There are currently 36 such units across the UK and Ireland, including paediatric facilities, although this review focuses on the management of adult patients. ${ }^{11}$

Several professional groups have written guidelines for the management of TBI. The first of these were published in $1984,{ }^{12}$ and were subsequently superseded by recommendations from the Society of British Neurosurgeons (SBNS) ${ }^{13}$ and the Royal College of Surgeons of England (RCS). ${ }^{14} 15$

The National Institute for Health and Clinical Excellence (NICE) produced the first version of its head injury guidelines in $2003 .{ }^{16}$ The recommendations - now the benchmark for care - were updated in 2007 to reflect new evidence. Amendments were made to the section about the transfer of patients to neurosurgical services, focusing on two particular aspects (See box 1$)^{4}$ :

1. Direct Transfer: The benefits of direct transport from the scene to a specialist neurosciences centre, compared with transport to the nearest DGH

2. Secondary Transfer: The benefits of patients with a clinically important brain injury not requiring surgery receiving treatment at a RNU after stabilisation at a DGH

The NICE recommendations about neurosurgical transfer raise issues about the capacity of RNUs, if more patients are to receive specialist care. The NICE guideline development group (GDG) acknowledged that there are currently not enough resources for all head injuries to go to a neurosciences centre, but suggested that the aspiration should be to improve the rate of transfer.

This review first critically evaluates the papers on which NICE based their recommendations about transfer for neurosurgical care. Subsequently, the literature about the configuration and capacity of emergency neurosurgical services in the UK, including bed capacity and the geographical organisation of services, is examined, in order to assess the implications of increasing the number of secondary transfers, as recommended by NICE.

\section{METHODS}

Three electronic databases (MEDLINE, EMBASE and CINAHL) were searched systematically to find 
Box 1 Summary of updated NICE guidance on transfer for neurosurgical care

Direct transfer (Recommendation 5.5.5)

The guideline development group (GDG) recognises that transporting patients with head injury directly to a neuroscience unit rather than a DGH would require a major shift of resources of between an additional 84000 and 105000 bed days to neurosurgery from the existing general surgical, orthopaedic, emergency department, paediatric and geriatric services that currently care for these patients. The GDG recognise that further research is needed in this area in order to identify benefits in transporting patients with head injury to a neuroscience unit or a DGH. Therefore, the GDG propose a research recommendation for this question.

\section{Secondary transfer (Recommendation 7.8.6)}

Local guidelines on the transfer of patients with head injuries should be drawn up between the referring hospital trusts, the neuroscience unit and the local ambulance service, and should recognise that:

- Transfer would benefit all patients with serious head injuries (GCS $\leq 8)$, irrespective of the need for neurosurgery

- If transfer of those who do not require neurosurgery is not possible, ongoing liaison with the neuroscience unit over clinical management is essential.

articles published between 1980 and 2008, discussing the provision of emergency neurosurgical care for adult head injuries in the UK. The search terms 'head injury' and 'brain injury' were used in combination with 'management', 'variations', 'regional', 'NICE head injury guidelines', and 'neurosurgery'.

The 'related articles' feature in PubMed was also used to search for articles, and the reference lists of other articles were checked for further references. The online archives of key publications, including the Emergency Medicine Journal and the British Journal of Neurosurgery, were searched using the same terms.

Eligibility criteria were defined prior to carrying out the search, and research articles, local and national published audits, and policy documents were included. Articles were identified by an initial search of the title and abstract. Full text articles relating to the provision of emergency neurosurgical services were then obtained for review.

As the review is specific to NHS care, the search included only papers relevant to the UK, published in English. To focus the review, articles addressing topics such as neurorehabilitation and technical neurosurgical management were excluded, as were other aspects of early head injury management, such as triage and assessment.

\section{RESULTS}

The details of the literature search are outlined in figure 1. One hundred and forty-four full text articles were identified for further analysis. Ten were excluded because the full text version could not be located, including three online reports that are no longer available. Eighty-six did not meet the entry criteria on closer scrutiny, most of which related only to minor head injuries or the challenges of implementing the guidance on CT scanning.

Fifty-eight papers were reviewed. This includes the seven papers cited by NICE in their review, which was limited to outcomes. Fifty-one further documents related to the provision of neurosurgical services, including nine on bed occupancy, eight on travel times to RNUs and 20 on transfer policies.
Total citations identified from electronic databases

(Medline, Embase, CINAHL)

$\mathrm{n}=3071$

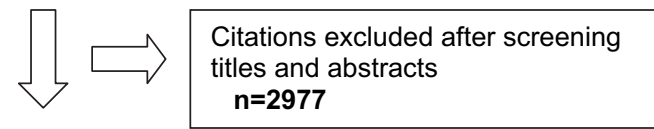

Articles retrieved for detailed evaluation

- From electronic databases: $n=93$

- From hand searching: $n=51$ $n=144$

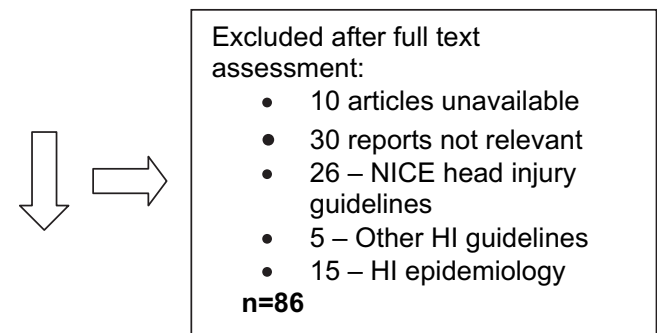

Articles included in review:
\[ 51-\text { Neurosurgical management } \]
$\cdot \quad 7$ papers cited by NICE
$\mathbf{n = 5 8}$

Figure 1 Selection of articles to review.

\section{NICE guidelines}

NICE undertook systematic literature reviews to identify papers relevant to two aspects of emergency neurosurgical care: direct transfer from the scene to a RNU, and secondary transfer of all patients with severe head injuries from DGHs to a RNU, irrespective of their need for surgery.

\section{Direct transfer}

According to NICE, a policy to transport all TBI patients directly to a specialist centre would require a shift of an additional 84000-105000 bed days to neurosurgery from the existing services that care for this group. They concluded that there is insufficient evidence to support this currently.

The two papers NICE cited to support this are summarised in table 1. Both are based on data from US trauma centres. Hannan et al compared mortality in patients in New York State taken directly to a trauma centre (with neurosurgical facilities), versus those taken to a non-trauma centre. ${ }^{17}$ Mortality rates were in favour of direct transfer. The second paper demonstrated that paediatric patients intubated in the field had worse outcomes than those intubated in hospital. ${ }^{18}$ However, the study was designed to examine the effect of place of intubation, not direct transport, as NICE acknowledged.

\section{Secondary transfer}

There was no uncertainty about the transfer of patients requiring surgery, but the GDG drew on four studies (see table 1) to recommend that all patients should ideally receive treatment in a neurosurgical unit, irrespective of their need for an operation. The first paper was a study of head injuries treated in hospitals contributing data to the UK Trauma Audit and Research Network (TARN) ${ }^{20}$ The case-mix adjusted odds of death for TBI 
Table 1 Papers cited in the NICE guidelines about neurosurgical transfer

\begin{tabular}{|c|c|c|c|c|c|}
\hline Paper & Study design & Source of data & No. of patients & Comparison & Outcomes \\
\hline $\begin{array}{l}\text { Hannan }{ }^{17} \\
(2005)\end{array}$ & $\begin{array}{l}\text { Retrospective observational } \\
\text { cohort study }\end{array}$ & $\begin{array}{l}\text { New York State Trauma } \\
\text { Registry, USA } \\
\text { (1996-1998) }\end{array}$ & $\begin{array}{l}2763 \text { head injured patients } \\
\text { (GCS }<14 \text { ) }\end{array}$ & $\begin{array}{l}\text { By ambulance destination: } \\
\text { 1. } 2272 \text { trauma centre } \\
\text { 2. } 491 \text { non-trauma centre }\end{array}$ & $\begin{array}{l}\text { Odds of mortality (1) vs (2): } \\
0.67(0.53 \text { to } 0.85)\end{array}$ \\
\hline $\begin{array}{l}\text { Pate }^{20} \\
(2005)\end{array}$ & $\begin{array}{l}\text { Prospective observational cohort } \\
\text { study }\end{array}$ & $\begin{array}{l}\text { UK Trauma Audit and } \\
\text { Research Network database } \\
(1996-2003)\end{array}$ & $\begin{array}{l}6921 \text { blunt head injuries } \\
\text { admitted to TARN hospitals } \\
\text { (any age) }\end{array}$ & $\begin{array}{l}\text { By treatment location } \\
\text { 1. } 2305 \text { non-neurosurgery } \\
\text { 2. } 2677 \text { neurosurgery unit }\end{array}$ & $\begin{array}{l}\text { Odds of mortality (1) vs (2): } \\
2.15 \text { (1.77 to } 2.60)\end{array}$ \\
\hline $\begin{array}{l}\text { Poon }^{21} \\
\text { (1991) }\end{array}$ & $\begin{array}{l}\text { Prospective observational cohort } \\
\text { study }\end{array}$ & $\begin{array}{l}\text { Single RNU in } \\
\text { Hong Kong } \\
\text { (1985-1989) }\end{array}$ & $\begin{array}{l}104 \text { patients requiring surgery } \\
\text { for EDH }\end{array}$ & $\begin{array}{l}\text { By transfer: } \\
\text { 1. } 71 \text { direct to RNU } \\
\text { 2. } 33 \text { transferred DGH }\end{array}$ & $\begin{array}{l}\text { Mortality rate: } \\
4 \% \text { (1) vs } 24 \% \text { (2) }\end{array}$ \\
\hline
\end{tabular}

DGH, district general hospital; EDH, extradural haematoma; GCS, Glasgow Coma Scale; RHISS, relative head injury severity scale; RNU, regional neurosciences unit; TARN, Trauma Audit and Research Network.

patients in non-neurosurgical centres was 2.15 times that of those who received specialist care; mortality rates were $26 \%$ higher. However, it was not clear which aspects of specialist neurointensive care improved outcome. The remaining papers NICE cited described results from other countries to support the case that all patients should receive specialist care. ${ }^{17} 2122$

The generalisability of the non-UK studies is questionable. For example, the paper by Hannan ${ }^{17}$ described care in New York State, where there is approximately four times the density of RNUs compared to the UK, so travel times are likely to be much shorter. ${ }^{23}$ The UK also remains the only First World country not to have a system of designated trauma centres currently.

The GDG called for more research on both transfer options, but the papers they cited highlight the difficulties of conducting rigorous research in this field. There is a paucity of randomised trials, and the emergency medicine literature is dominated by observational cohort studies and small case series, which may be subject to confounding and bias.

The aim of NICE guidance is to maximise the quality and consistency of patient care, but this document has been criticised because the evidence base for many of the other recommendations is limited and from non-UK settings. ${ }^{24}$ Resource availability was also outside their terms of reference, ${ }^{25}$ prompting calls for a 'more realistic' alternative taking this into account. $^{26}$

\section{Neurosurgical facilities}

Only $53 \%$ of TBI patients who receive care at a DGH are transferred to a RNU. ${ }^{20}$ Some may not be suitable for further intervention, but would it be feasible for more patients to be transferred to receive specialist neurosurgical care, particularly when over half would not require surgery?

Only $9 \%$ of DGHs are able to transfer all their TBI patients for specialist care, due to bed shortages and local policies. ${ }^{27}$ Admission to neurosurgical units is currently governed by the availability of facilities, and patients with operable lesions are understandably given priority, but this has important implications for the implementation of the NICE guidance.

According to an audit carried out for the Department of Health in 2005, neurocritical care bed occupancy was consistently over $90 \%$, with demand outstripping supply by $9-22 \%$ across units in England and Wales. Twenty-three per cent of head injury patients were managed in non-specialist critical care units at that time. ${ }^{28}$ In another survey, ${ }^{9}$ only 43 neurocritical care beds were available nationally - far from sufficient to cope with the projected 28.6 head injuries per day, when trauma forms only part of the neurosurgical workload. The same study demonstrated large regional variations in bed availability.

Neurosurgical workload increased by more than 3\% annually between 1993 and 1999, but this was not matched by investment in facilities. ${ }^{29}$ In 1993, the SBNS proposed a target of 30 neurosurgical beds per million population as the minimum safe standard for 2000, but only five out of 37 units met this target by 1999, with some working at less than 15 beds per million. The same document also proposed a target of four dedicated neurosurgical critical care beds per million population, but only four out of 37 units met this target by 1999. There was again wide regional variation in the availability of both types of bed and, where resources are poorest, emergency work was carried out at the expense of waiting list cases, threatening equity of access to both trauma and elective patients. ${ }^{3}$

Twenty per cent of neurosurgical bed days were consumed by patients who did not require acute management. ${ }^{10}$ In one case, a lack of beds led to $33 \%$ of elective cases being cancelled over 1 month. ${ }^{30}$ The main reasons were delays in repatriation to the referring hospital, accessing theatre space or undergoing radiological investigations. The problem was compounded by the poor availability of rehabilitation services. ${ }^{31}$

Thirty per cent of Emergency Department (ED) consultants were unhappy about difficulties they faced in arranging referrals. ${ }^{32}$ However, there have been some successful attempts to strengthen the links between RNUs and the hospitals that they serve, notably in the Eastern region of England, ${ }^{33}$ with policies in place in other areas to facilitate the swift transfer of all appropriate patients, regardless of RNU bed status.

In the National Confidential Enquiry into Patient Outcome and Death (NCEPOD) review of trauma care provision in 1999 , $16.2 \%$ patients with moderate or severe head injuries had no evidence of neurosurgical referral, let alone transfer. However, the authors acknowledge that within this group it is possible that consultation was not undertaken due to the extent of injuries. ${ }^{34}$ 


\section{Geography and transfer times}

The report Safe Neurosurgery 2000, called for a maximum surface journey time to a neurosurgical unit of $2 \mathrm{~h}$, if equity of access is to be maintained. ${ }^{3}$ However, the geographical distribution of services in the UK has evolved due to local circumstances, rather than central planning.

The pathophysiology of traumatic brain injury is described in terms of primary and secondary injury. Primary injury is the damage sustained by the brain at the moment of impact. Secondary injury is any detrimental event that occurs subsequently, including hypotension and hypoxaemia, so adequate resuscitation is vital. The time taken for transfer impacts on the time to definitive management of the primary injury and the risk of secondary insults. Patients with an operable injury have a better outcome if their lesion is surgically evacuated within $4 \mathrm{~h}^{35}$

Although $33 \%$ of EDs were within 10 miles of the nearest neurosurgical unit, $12 \%$ were over 50 miles away and the national average was 23 miles, according to the Galasko report in 1999. ${ }^{14}$ Table 2 shows four further reports that described the range of regional units. Travel times meant that in one survey only six out of 43 (14.0\%) patients transferred secondarily had an operation within $4 \mathrm{~h}$ of injury, compared with 22 out of 33 $(66.7 \%)$ taken directly to the neurosurgical centre. ${ }^{34}$

There are also wide variations in the range of specialist centres nationally. In the catchment areas for urban centres, patients are a median distance of $10-15 \mathrm{~km}$ away, whereas in largely rural areas patients are a median of $50 \mathrm{~km}$ away. Some centres operate between these extremes, with a mixed population a median distance of $20 \mathrm{~km}$ away, but an IOR of $5-80 \mathrm{~km}$. ${ }^{39}$ Such variations mean that achieving equity of access even with respect to the same centre is difficult, particularly in rural areas. There are no data about whether distance from the RNU affects the likelihood of patients being transferred, or about the impact of transfer times in patients with non-operable brain injuries.

\section{Delays in transfer}

Delays in patient transfer are not solely due to travel times, but often also occur at the DGH, either from failure to institute appropriate treatment for non-cranial injuries or in realising transfer was necessary. ${ }^{40}$ Delays in CT scanning and time waiting for an ambulance are also important. ${ }^{41}$

Twenty per cent of head injury patients were still not scanned in a timely fashion, even though $95 \%$ of hospitals now have $24-\mathrm{h}$ access to CT imaging. Delays were primarily due to organisational factors, such as waiting for staff or access to the CT scanner. ${ }^{34}$ Moreover, a recent study demonstrated that no single step in the transfer process was responsible for all delays, nor were any single steps consistently performed within an acceptable time period. ${ }^{37}$

Systems to electronically transfer CT images between centres have also reduced the number of unnecessary transfers, but $13 \%$ of hospitals without on-site neurosurgery still do not have effective image transfer systems, so scans must be sent by courier, causing further delays. ${ }^{27}$

\section{Hazards of secondary transfer}

Although often necessary, transfer is not without risk, as NICE acknowledged. Avoidable factors contributing to death in patients transferred to a RNU have been reported for many years, highlighting the need for adequate resuscitation prior to departure. ${ }^{42-44}$ As the management of a head injury often takes precedence, the initial first-line management of other injuries such as long bone fractures can be unsatisfactory. ${ }^{45-49}$ The problem seems to have persisted, despite the implementation of the Advanced Trauma Life Support (ATLS) guidelines. ${ }^{41}$ However, most of the papers about the risk of transfer again involved a limited number of patients, and data from only one regional centre.

In another study, $63 \%$ of transfers required further intervention at the second hospital to complete resuscitation. ${ }^{50}$ Several other papers identify problems with the care of patients being transferred, particularly as transfers often take place out of hours $^{51}$ and vital equipment may not be available. ${ }^{52}$ The NCEPOD trauma audit described arrangements for transfers as 'haphazard,' with deficiencies in local protocols, use of national guidelines, consultant oversight and documentation. ${ }^{34}$

If more patients with TBI are to benefit from neurosurgical care, closer attention must be paid to adequate resuscitation and assessment prior to transfer. Consideration also needs to be given to staff training and the availability of suitable equipment. ${ }^{53}$

\section{DISCUSSION}

Almost 10 years ago, the report published by the Royal College of Surgeons concluded that head-injured patients were not receiving consistent and optimal care. ${ }^{14}$ More recent reports suggest high-quality care is still not available, ${ }^{27}$ and there has also been little change in mortality, despite technical progress. ${ }^{6}$

Care is currently hampered by a number of barriers including the shortage of specialist beds, ${ }^{9} 30$ variations in travel times, and 'haphazard' transfer arrangements. Although the lack of neurosurgical beds is not a new problem, there has been little action to improve the situation. ${ }^{3} 54$

The evidence NICE cited to support their recommendations is based on four cohort studies, three of which were carried out outside the UK. It is questionable whether this evidence is relevant to the NHS. However, there is growing belief that patients with TBI have better outcomes if they are managed in a RNU, although the specific reasons for this are still unclear. Although NICE recognised that it would not be feasible for all patients to be transferred, they suggested the number should be increased.

As well as demonstrating the paucity of evidence behind the NICE guidelines on neurosurgical transfers, this review goes on to raise questions about the operational implications of the recommendations. It is suggested that increasing the number of secondary transfers could worsen inequalities of access for elective patients, as a consequence of prioritising the admission of trauma patients. Equity of access between centres may also be

Table 2 Demographics of selected regional neurosurgery services

\begin{tabular}{|c|c|c|c|c|c|}
\hline Unit & $\begin{array}{l}\text { No. of } \\
\text { hospitals } \\
\text { served }\end{array}$ & $\begin{array}{l}\text { Population } \\
\text { served } \\
\text { (million) }\end{array}$ & Range of hospitals & Transfer times & Notes \\
\hline Stoke-on-Trent ${ }^{19}$ & 5 & 1.7 & - & $20 \min -65 \min$ & \\
\hline Salford ${ }^{36}$ & 11 & 3.2 & Less than 25 miles & Median $5.25 \mathrm{~h}$ for EDH, $6.0 \mathrm{~h}$ for SDH & Local resources prevent all patients being transferred \\
\hline Cambridge $^{37}$ & 8 & 3.0 & Max 76 miles Half $>40$ miles & Median $5.4 \mathrm{~h}$ & $1 / 24$ patients operated on in under $4 \mathrm{~h}$ \\
\hline Southampton ${ }^{38}$ & 8 & 3.0 & Range $19-85 \mathrm{~km}$ & Mean time to decompression $5.0 \mathrm{~h}$ & \\
\hline
\end{tabular}


compromised, unless attempts are made to improve service provision in centres where facilities are most stretched. ${ }^{34}$ Finally, it is recommended that urgent work is needed to improve the quality of transfer procedures, before the number of transfers is increased.

\section{Limitations}

This review has drawn together, for the first time, several important nationwide evaluations, such as the Neurocritical Care Stakeholder Report, and the NCEPOD trauma report. These reports were not cited by NICE.

However, this review illustrates some of the difficulties in carrying out research into trauma care. The diverse range of documents reviewed, including policy documents and audits meant that it was not possible to apply a uniform indicator of the quality of these papers. However, the majority of papers identified referred to single centre audits, involving small numbers of patients and so their validity and generalisability should therefore be interpreted with caution.

The review has not addressed the particular challenges of managing paediatric head injuries. Further research is required to explore the economic aspects of providing evidence-based care.

\section{Recommendations and further research}

Work undertaken by the Trauma Action Research Network (TARN) must be welcomed, but more detailed evidence about patients in UK settings is required. The TARN paper cited by NICE, for example, demonstrated that patients treated in a RNU had better outcomes, but unfortunately did not report this information according to whether patients were taken to the RNU directly or secondarily. Currently, only a minority of hospitals routinely report data to TARN and this is especially poor in London, so continued efforts to improve recruitment, and strengthen the data quality should be supported. Establishing the aspects of 'packages of specialist care' that improve outcomes must also be a priority, especially for patients who do not require surgery.

Following the example of networks such as the head injury group in the Eastern region of England, all head injury networks should be seeking to strengthen communication between regional units and their local hospitals. The Neurocritical Care Network is also seeking to link all the neurocritical care units in the UK and to highlight areas of good practice. There is limited evidence about the impact of local variations in practice, so these should be explored. The Intensive Care National Audit and Research Centre (ICNARC) is currently developing a tool for risk adjustment in neurosciences (RAIN), which will hopefully allow case-mix adjusted comparisons between units. The proposed introduction of trauma networks in London may also highlight important lessons to be learnt.

Work is also needed to build consensus about the place of the NICE guidance in a healthcare system where resources are limited. In this case the evidence base is weak, and it is not currently feasible to implement the recommendations fully without major investment or service re-design. However, if the guidelines are the accepted gold standard, failure to meet them could ultimately pose both risk management and potential medico-legal issues.

Investment in both acute neurosurgical services and rehabilitation facilities is clearly needed, even without the recent guidelines. Specific areas to consider are clearer local protocols for transfer, and work to reduce delays in departure. Greater attention to repatriating patients, as well as discharge to rehab would also help reduce the pressure on neurosurgical facilities.

\section{CONCLUSIONS}

Concerns have been raised for many years about the emergency care available for patients with severe head injuries in the UK, particularly with regard to access to neurosurgical services. This review highlights the inadequate capacity in the system to meet current demand for neurosurgical care, let alone develop services further and implement the NICE recommendation that more patients should be transferred.

It is clear that many patients still do not receive the best possible care. Without substantial commitment from the emergency medicine community, neurosurgeons and commissioners, the care of patients with severe head injury in the UK will continue to be compromised.

Acknowledgements The authors would like to thank Dr Francesca Perlman and Dr Bethan Davies for comments on early drafts of the manuscript.

Competing interests None.

Provenance and peer review Not commissioned; externally peer reviewed.

\section{REFERENCES}

1. Thornhill S, Teasdale G, Murray G, et al. Disability in young people and adults one year after head injury: prospective cohort study. BMJ 2000;320:1631-5.

2. Kay A, Teasdale G. Head injury in the United Kingdom. World J Surg 2001;25:1210-20.

3. Anon. Safe Neurosurgery 2000. London: Society of British Neurological Surgeons, 1999.

4. Anon. Head injury: triage, assessment, investigation and early management of head injury in infants, children and adults. (NICE clinical guideline No 56). London: Nationa Institute for Health and Clinical Excellence, 2007. (http://guidance.nice.org.uk/CG56)

5. Seeley HM, Hutchinson $P$, Maimaris $C$, et al. A decade of change in regional head injury care: a retrospective review. Br J Neurosurg 2006;20:9-21.

6. Lecky FE, Woodford M, Bouamra 0 , et al. Lack of change in trauma care in England and Wales since 1994. Emerg Med J 2002;19:520-3.

7. Chaudhry MA, Santarius T, Wilson L, et al. Head injuries: a prospective observational study evaluating the potential impact of the Galasko report on Accident and Emergency departments. Injury 2003;34:853-6.

8. Kerr J, Smith R, Gray S, et al. An audit of clinical practice in the management of head injured patients following the introduction of the Scottish Intercollegiate Guidelines Network (SIGN) recommendations. Emerg Med J 2005:22:850-4.

9. Crimmins DW, Palmer JD. Snapshot view of emergency neurosurgical head injury care in Great Britain and Ireland. J Neurol Neurosurg Psychiatr 2000;68:8-13.

10. Bradley LJ, Kirker SGB, Corteen E, et al. Inappropriate acute neurosurgical bed occupancy and short falls in rehabilitation: implications for the National Service Framework. Br J Neurosurg 2006;20:36-9.

11. The Society of British Neurological Surgeons. Neurosurgical Centres. http: \lwww.sbns.org.uk. (accessed July 2009)

12. Briggs $\mathbf{M}$, Clark $P$, Crockard $A$, et al. Guidelines for initial management of head injury Suggestions from a group of neurosurgeons. BMJ 1984;288:983-5.

13. Bartlett J, Kett-White R, Mendelow AD, et al. Recommendations from the Society of British Neurological Surgeons. British J Neurosurg 1998:12:349-52.

14. Anon. Report of the Working Party on Head Injuries. London: The Royal College of Surgeons of England, 1999.

15. Royal College of Surgeons of England Trauma Committee. The Royal College of Surgeons of England: a position paper on the acute management of patients with head injury (2005). Ann R Coll Surg Engl 2005;87:323-5.

16. Anon. Head injury: Triage, assessment, investigation and early management of head injury in infants, children and adults. London: National Institute for Health and Clinical Excellence, 2003. (NICE clinical guideline No 4).

17. Hannan E, Farrell L, Cooper A, et al. Physiologic trauma triage criteria in adult trauma patients: Are they effective in saving lives by transporting patients to trauma centers? J Am Coll Surg 2005;200:584-92.

18. DiRusso SM, Sullivan T, Risucci D, et al. Intubation of pediatric trauma patients in the field: predictor of negative outcome despite risk stratification. J Trauma 2005:59:84-90.

19. Stevenson MD, Oakley PA, Beard SM, et al. Triaging patients with serious head injury: results of a simulation evaluating strategies to bypass hospitals without neurosurgical facilities. Injury 2001;32:267-74.

20. Patel HC, Bouamra 0, Woodford M, et al. Trends in head injury outcome from 1989 to 2003 and the effect of neurosurgical care: an observational study. Lancet 2005;366:1538-44.

21. Poon WS, Li AK. Comparison of management outcome of primary and secondary referred patients with traumatic extradural haematoma in a neurosurgical unit. Injury 1991;22:323-5.

22. Härtl R, Gerber $L M$, lacono $L$, et al. Direct transport within an organized state trauma system reduces mortality in patients with severe traumatic brain injury. J Trauma 2006; 60:1250-6 
23. NICE Head Injury Guidelines-Consultation Comments (http://www.nice.org.uk/ nicemedia/pdf/HeadlnjuryUpdateConsultationComments.pdf). (accessed July 2009).

24. Leaman AM. The NICE guidelines for the management of head injury: the view from a district hospital. Emerg Med J 2004:21:400.

25. Yates DW. The NICE head injury guidelines. Emerg Med J 2003;20:117.

26. Swann IJ, Kelliher T, Kerr J. Are we ready for NICE head injury guidelines in Scotland? Emerg Med J 2004;21:401-2.

27. Browne J, Coats TJ, Lloyd DA, et al. High quality acute care for the severely injured is not consistently available in England, Wales and Northern Ireland: report of a survey by the Trauma Committee, The Royal College of Surgeons of England. Ann R Coll Surg Eng/ 2006;88:103-7.

28. Neurocritical Care Stakeholder Group. Neurocritical Care Capacity and Demand, Neuroanaesthesia Society of Great Britain and Ireland (NASGBI), London. 2006. (http://www.nasgbi.org.uk/resources/1/Documents/ neurocriticalcaresnapshotauditfinal.doc) (accessed July 2009)

29. White BD, Buxton N. Safe neurosurgery-How are we doing three years on? British J Neurosurg 1998;12:329-34.

30. Ashkan K, Edwards RJ, Bell BA. Crisis in resources: a neurosurgical prospective. Br J Neurosurg 2001;15:342-6.

31. Chelvarajah R, Lee JK, Chandrasekaran S, et al. A clinical audit of neurosurgical bed usage. Br J Neurosurg 2007;21:610-3.

32. Swann IJ, Walker A. Who cares for the patient with head injury now? Emerg Med J 2001;18:352-7.

33. Seeley HM, Maimaris C, Hutchinson PJ, et al. Standards for head injury management in acute hospitals: evidence from the six million population of the Eastern region Emerg Med J 2006;23:128-32.

34. Anon. Trauma: who cares? London: National Confidential Enquiry into Patient Outcome and Death, 2007.

35. Seelig JM, Becker DP, Miller JD. Traumatic acute subdural haematoma. NEJM 1981;304:1511-17.

36. Leach P, Childs C, Evans J, et al. Transfer times for patients with extradural and subdural haematomas to neurosurgery in Greater Manchester. $\mathrm{Br} J$ Neurosurg. 2007;21:11-5

37. Sergides IG, Whiting G, Howarth S, et al. Is the recommended target of 4 hours from head injury to emergency craniotomy achievable? Br J Neurosurg 2006;20:301-5.

38. Bulters D, Belli A. A prospective study of the time to evacuate acute subdural and extradural haematomas. Anaesthesia 2009:64:277-81.
39. Tasker RC, Morris KP, Forsyth RJ, et al. Severe head injury in children: emergency access to neurosurgery in the United Kingdom. Emerg Med J 2006;23:519-22.

40. Marsh H, Maurice-Williams RS, Hatfield R. Closed head injuries: where does delay occur in the process of transfer to neurosurgical care? $\mathrm{Br} \mathrm{J}$ Neurosurg 1989;3:13-9.

41. Price SJ, Suttner N, Aspoas AR. Have ATLS and national transfer guidelines improved the quality of resuscitation and transfer of head-injured patients? A prospective survey from a Regional Neurosurgical Unit. Injury 2003;34 834-8.

42. Rose J, Valtonen S, Jennett B. Avoidable factors contributing to death after head injury. BMJ 1977;2:615-18.

43. Jeffreys RV, Jones JJ. Avoidable factors contributing to the death of head injury patients in general hospitals in Mersey Region. Lancet 1981;2:459-61.

44. Gentleman D, Jennett B. Hazards of inter-hospital transfer of comatose head-injured patients. Lancet 1981:2:853-4.

45. Gentleman D, Jennett B, MacMillan R. Death in hospital after head injury without transfer to a neurosurgical unit: who, when, and why? Injury 1992:23:471-4.

46. Dunn LT. Secondary insults during the interhospital transfer of head-injured patients: an audit of transfers in the Mersey Region. Injury 1997;28:427-31.

47. Hicks IR, Hedley RM, Razis P. Audit of transfer of head-injured patients to a standalone neurosurgical unit. Injury 1994;25:545-9.

48. Lambert SM, Willett K. Transfer of multiply-injured patients for neurosurgical opinion: a study of the adequacy of assessment and resuscitation. Injury 1993:24:333-6.

49. Grant PT, Shrouder S. Initial assessment and outcome of head injured patients transferred to a regional neurosurgical service: what do we miss? J Accid Emerg Med 1997:14:10-2

50. O'Connor PM, Steele JA, Dearden $\mathrm{CH}$, et al. The accident and emergency department as a single portal of entry for the reassessment of all trauma patients transferred to specialist units. J Accid Emerg Med 1996;13:9-10.

51. Gray A, Gill S, Airey M, et al. Descriptive epidemiology of adult critical care transfers from the emergency department. Emerg Med J 2003;20:242-6.

52. Stevenson A, Fiddler C, Craig M, et al. Emergency department organisation of critica care transfers in the UK. Emerg Med J 2005;22:795-8.

53. Gray A, Bush S, Whiteley S. Secondary transport of the critically ill and injured adult. Emerg Med J 2004;21:281-5.

54. Hutchinson PJ. Future perspectives in the acute management of head injury. Br J Surg 2003;90:769-71.

\section{Emergency Medicine Questions (EMOs)}

\section{Theme: Acute bacterial meningitis}

\section{QUESTION 1}

Which of the following are true regarding the aetiology of acute bacterial meningitis $(\mathrm{ABM})$ ?

a. Listeria monocytogenes is a common cause of $\mathrm{ABM}$ in neonates.

b. Childhood immunisation programs have reduced the incidence of Haemophilus influenza $b$ (Hib) meningitis by up to $50 \%$ in developed countries.

c. Tuberculous meningitis is usually caused by direct haematogenous seeding.

d. Children with cochlear implants have an increased risk of ABM

\section{QUESTION 2}

Which of the following are true regarding the diagnosis of acute bacterial meningitis (ABM)?

a. The classic triad of fever, neck stiffness and altered conscious state are present in less than two thirds of patients with ABM.

b. There is a high likelihood of precipitating cerebral herniation if a lumbar puncture is performed on patients with suspected $\mathrm{ABM}$ and papilloedema.

c. CT head reliably identifies those at risk of herniation during LP. d. Presence of a purpuric rash in a patient with ABM is highly specific and moderately sensitive for Neiseria meningitides septicemia.

\section{QUESTION 3}

Which of the following are true regarding the treatment of acute bacterial meningitis $(\mathrm{ABM})$ ?

a. Tight fluid control aiming at replacement of approximately $60 \%$ of daily basal requirements is important for the first $48 \mathrm{~h}$.

b. Dexamethasone is recommended for routine therapy in suspected ABM in children and adults.

c. Dexamethasone should be administered after CT has excluded a focal cerebral lesion.

d. Rifampicin should be offered to all emergency department staff who come into contact with a case of meningococcal meningitis.

See page 206 for answers.

\section{Davey}

Provenance and peer review Commissioned; not externally peer reviewed.

Emerg Med J 2010:27:178. doi:10.1136/emj.2010.092395 